Research Article

\title{
Current trends in highly active anti-retroviral therapy in an anti- retroviral therapy centre attached to a remote government medical college of Maharashtra, India: a retrospective study
}

\author{
Pravin S. Rathod ${ }^{1 *}$, Praveenkumar T. Patil ${ }^{1}$, Rekha P. Lohar ${ }^{2}$, A.W. Patil ${ }^{1}$
}

\begin{abstract}
${ }^{1}$ Department of Pharmacology, SBH GMC, Dhule, Maharashtra, India

${ }^{2}$ Department of Community Medicine, SBH GMC, Dhule, Maharashtra, India

Received: 01 April 2016

Accepted: 07 May 2016

*Correspondence to:

Dr. Pravin S. Rathod,

Email: drpslohar@

rediffmail.com

Copyright: () the author(s), publisher and licensee Medip Academy. This is an openaccess article distributed under the terms of the Creative Commons Attribution NonCommercial License, which permits unrestricted noncommercial use, distribution, and reproduction in any medium, provided the original work is properly cited.
\end{abstract}

\begin{abstract}
Background: Highly active anti-retroviral therapy (HAART) became the keystone of national AIDS program. There is lack of awareness and inadequate training about drug safety monitoring among health care professionals in India. Hence, the present study was carried out to study current trends in HAART and pattern of associated adverse drug reactions.

Methods: A retrospective observational study was conducted at an antiretroviral therapy (ART) Centre. A total of 151 HIV/AIDS Patients (old and new cases) receiving HAART during July 2015 to December 2015 were randomly included in the study. Causality and severity assessment of adverse drug reactions (ADRs) was done by using Naranjo's ADR causality scale and modified Hartwig and Siegel scale respectively. The data was computed using MS Excel and descriptive results were expressed as counts and percentages. The study was approved by institutional ethics committee.

Results: The prevalence of HIV/AIDS infection was higher in adult males $(51.66 \%)$. Zidovudine+lamivudine+nevirapine (ZLN) was the most commonly prescribed HAART combination. Out of 132 ADRs reported, $76.52 \%$ of the ADRs were related to haematological system and ZLN was the commonest combination causing ADRs. 90.91\% ADRs belong to possible category on causality assessment and $68.94 \%$ of the ADRs were of moderate severity. Tuberculosis $(28.47 \%)$ was the commonest diagnosed opportunistic infection among the HIV/AIDS patients.

Conclusions: The prescribing pattern of HAART regimens was in accordance with national guidelines for antiretroviral therapy. We recommend a pharmacovigilance system for sustainable management of ADRs in HIV/AIDS patients as we found under reporting of ADRs.
\end{abstract}

Keywords: HIV/AIDS, HAART, ADRs, Opportunistic infections

\section{INTRODUCTION}

Infection with human immunodeficiency virus (HIV) and its progression to acquired immunodeficiency syndrome (AIDS) have been a global crisis and a big challenge to the healthy living of human beings today. It may derail socio-economic development because of its huge influence on family stability, life expectancy and economic development. ${ }^{1}$

Today, around 4.87 million people are living with HIV in South, East, and South-east Asia. In India, an estimated
$0.1 \%$ of adults aged 15-49 years are living with HIV; however, with a population of around 1 billion, this actually equates to 2.3 million adults living with HIV in India. $^{2,3}$

Growing socio-economic burden of the disease in India led to the foundation of National AIDS Control Organization (NACO) in the year 1986 and subsequently in the formation of National AIDS program in the year 1987. Antiretroviral therapy (ART) became the keystone of national AIDS program. Highly active antiretroviral therapy (HAART) presently is a lifelong therapy. The 
introduction of HAART has led to a significant reduction in AIDS related morbidity and mortality. ${ }^{4}$

More than 20 approved ART drugs in 6 mechanistic classes are available to design combination regimens. These 6 classes include the nucleoside/nucleotide reverse transcriptase inhibitors (NRTIs), the non-nucleoside reverse transcriptase inhibitors (NNRTIs), the protease inhibitors (PIs), the fusion inhibitors (FIs), the CCR5 antagonists, and the integrase strand transfer inhibitors (INSTIs). ${ }^{5}$

Most of the drugs which are available and approved for use in HAART have some or the other adverse effects, thus treatment of HIV infection has become a complicated balancing act between the benefits of durable HIV suppression and the risks of drug toxicity. ${ }^{6}$

The documented side effects of these drugs are: zidovudine causes bone marrow suppression leading to anaemia and neutropenia. Stavudine causes nausea, peripheral neuropathy, pancreatitis and lipoatrophy. nevirapine causes skin rash, steven jhonson syndrome and hepatitis. Efavirenz causes malformations in foetuses so contraindicated in pregnancy. Skin rash occurred in $10 \%$ of patients. Lamivudine has minimum toxicity. Most common adverse effects of lamivudine were diarrhoea, malaise, fatigue, headache, and sleep disturbances. ${ }^{7}$

Unfortunately, up to $25 \%$ of all patients discontinue their initial HAART regimen because of treatment failure, toxic effects or noncompliance within the first 8 months of therapy. ${ }^{8}$

Pharmacovigilance of ART drugs is significant in many ways. It is, therefore, necessary that a systemic inquiry should be undertaken at various levels to elicit the ADR profile of ART in details. This should facilitate the management of an individual patient to a greater level of satisfaction. $^{9}$

Although the therapeutic goals of ART include achieving and maintaining viral suppression and improving immune function, an overall goal should be to select a regimen that is not only effective but also is safe. This requires consideration of not only the toxicity potential of the ARV drugs but also an individual patient's underlying conditions, concomitant medications, and prior history of drug intolerances.

Also there is a lack of awareness and inadequate training about drug safety monitoring among health care professionals in India. Often ADRs go unnoticed or are not reported. Monitoring and reporting of ADRs to ART is very important.

Hence, the present study was carried out to collect demographic details of HIV/AIDS patients, current trends in prescribing anti-retroviral drugs and to study the incidence and pattern of adverse drug reactions associated with antiretroviral therapy in an anti-retroviral therapy (ART) centre attached to a remote government medical college of Maharashtra, India.

\section{METHODS}

This was a retrospective observational study conducted at a National AIDS control organization (NACO) approved, anti-retroviral therapy (ART) centre attached to SBH Government Medical College, Dhule, Maharashtra, India. A total of $151 \mathrm{HIV/AIDS}$ patients (old and new cases) receiving highly active anti-retroviral therapy (HAART) during July 2015 to December 2015 were randomly included in the study. Pediatric and pregnant women receiving anti-retroviral therapy were excluded from the study. Patient's details such as name, age, sex, marital status, mode of transmission, CD4 count, ART regimens and adverse events (AEs) to the anti-retroviral drugs were collected from the case record sheets maintained in the ART Centre. Causality assessment of AEs by using Naranjo's ADR Causality scale and the severity assessment of ADRs was done by using Modified Hartwig and Siegel scale. ${ }^{10,11}$ The data was computed using MS Excel and descriptive results were expressed as counts and percentages. The study was approved by institutional ethics committee.

All the information collected was kept confidential and the identity of the HIV/AIDS patients was not disclosed.

\section{RESULTS}

The prevalence of HIV/AIDS infection was higher in males $(51.66 \%)$ than females $(48.34 \%)$. The prevalence of HIV/AIDS infection was higher in 26-35 years age group $(51.66 \%)$ followed by $36-45$ age group $(27.15 \%) .70 .19 \%$ of the patients were married and $19.87 \%$ patients were widowed. The most common mode of HIV/AIDS infection transmission was heterosexuality (94.04\%). $78.81 \%$ of the HIV/AIDS patients had CD4 counts less than 250 cells $/ \mu 1$ at the time of starting anti-retroviral therapy (Table 1).

Graph 1 shows $31.13 \%, 29.80 \%$ and $29.14 \%$ of the HIV/AIDS patients were distributed in the WHO clinical stages I, II and III respectively.

Zidovudine+lamivudine+nevirapine (ZLN) (86.75\%) were the most commonly given HAART combination followed by tenofovir+lamivudine+effavirenz (TLE) $(36.42 \%)$ combination (Table 2$)$.

Out of 132 ADRs reported, $76.52 \%$ of the ADRs related to hematological organ system (Graph 2) and zidovudine+lamivudine+nevirapine $(56.82 \%)$ was the commonest HAART combination causing the hematological ADRs mainly anemia (Table 3). 
Table 1: Socio-demographic characteristics of patients receiving highly active anti-retroviral therapy.

\begin{tabular}{|c|c|c|c|}
\hline Variable & & $\mathbf{n}$ & Percentage \\
\hline \multirow{2}{*}{ Gender } & Male & 78 & 51.66 \\
\hline & Female & 73 & 48.34 \\
\hline \multirow{5}{*}{ Age } & $15-25$ years & 14 & 9.27 \\
\hline & 26-35 years & 78 & 51.66 \\
\hline & $36-45$ years & 41 & 27.15 \\
\hline & $46-55$ years & 14 & 9.27 \\
\hline & $>55$ years & 04 & 2.65 \\
\hline \multirow{4}{*}{$\begin{array}{l}\text { Marital } \\
\text { status }\end{array}$} & Married & 106 & 70.19 \\
\hline & Widowed & 30 & 19.87 \\
\hline & Single & 13 & 8.61 \\
\hline & Divorced & 02 & 1.32 \\
\hline \multirow{5}{*}{$\begin{array}{l}\text { Mode of } \\
\text { transmission }\end{array}$} & Heterosexual & 142 & 94.04 \\
\hline & $\begin{array}{l}\text { Probable unsafe } \\
\text { injection }\end{array}$ & 03 & 1.99 \\
\hline & Mother to child & 03 & 1.99 \\
\hline & Blood transfusion & 02 & 1.32 \\
\hline & Unknown & 01 & 0.66 \\
\hline \multirow{4}{*}{$\begin{array}{l}\text { Education } \\
\text { status }\end{array}$} & Illiterate & 30 & 19.87 \\
\hline & Primary & 33 & 21.85 \\
\hline & Secondary & 55 & 36.42 \\
\hline & College & 33 & 21.85 \\
\hline \multirow{2}{*}{ CD4 count } & $<250$ cells $/ \mu 1$ & 119 & 78.81 \\
\hline & $\geq 250$ cells $/ \mu 1$ & 32 & 21.19 \\
\hline
\end{tabular}

$\mathrm{n}=$ No. of patients

Total number of patients $=151$

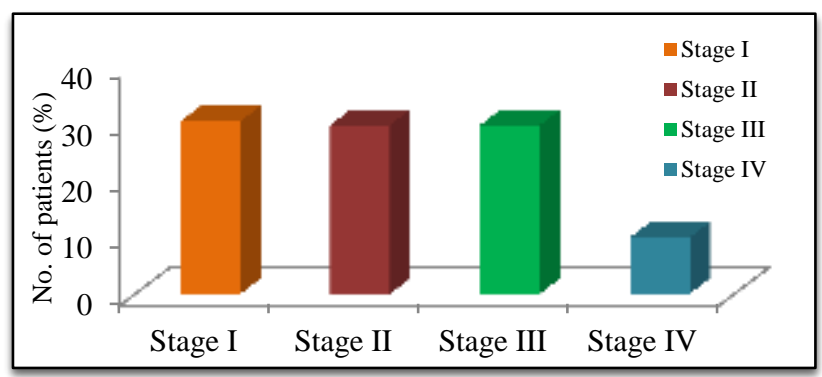

Figure 1: WHO Clinical stage distribution of patients receiving highly active anti-retroviral therapy.

Table 2: Different HAART combinations and their frequency of prescription among HIV/AIDS patients.

\begin{tabular}{|lll|}
\hline \multicolumn{1}{|c}{ HAART combination } & $\begin{array}{l}\text { Frequency } \\
\text { of } \\
\text { prescription }\end{array}$ & $\%$ \\
\hline zidovudine+lamivudine+nevirapine & 131 & 86.75 \\
\hline tenofovir+lamivudine+ effavirenz & 55 & 36.42 \\
\hline stavudine+ lamivudine + nevirapine & 52 & 34.44 \\
\hline zidovudine+lamivudine+ effavirenz & 40 & 26.49 \\
\hline tenofovir+lamivudine+nevirapine & 38 & 25.17 \\
\hline stavudine+ lamivudine +effavirenz & 15 & 9.93 \\
\hline abacavir+ lamivudine+nevirapine & 01 & 0.66 \\
\hline
\end{tabular}

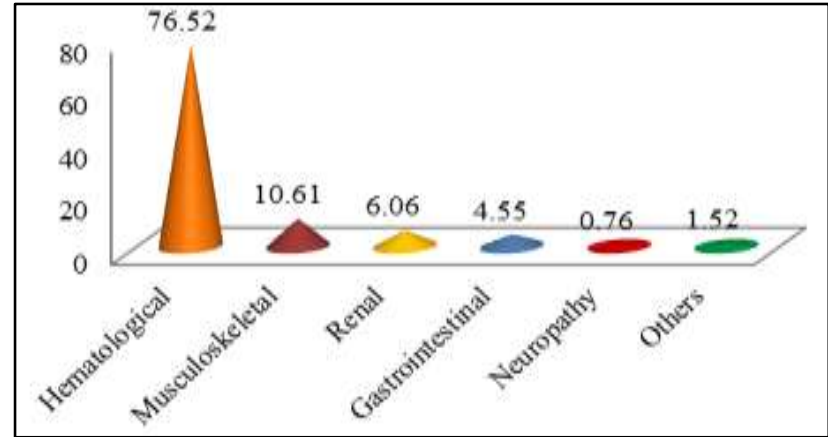

Figure 2: ADR patterns among patients receiving HAART.

Table 3: Characteristics details of adverse drug reactions among patients receiving HAART.

\begin{tabular}{|c|c|c|c|}
\hline $\begin{array}{l}\text { HAART } \\
\text { combination }\end{array}$ & ADR & $\mathbf{n}$ & $\%$ \\
\hline \multirow{9}{*}{ ZLN } & Anaemia & 75 & 56.82 \\
\hline & Skin rash & 09 & 6.82 \\
\hline & Raised RFT & 03 & 2.27 \\
\hline & Nausea & 02 & 1.51 \\
\hline & Vomiting & 02 & 1.51 \\
\hline & Jaundice & 01 & 0.76 \\
\hline & Hepatomegaly & 01 & 0.76 \\
\hline & Fever & 01 & 0.76 \\
\hline & Fatigue & 01 & 0.76 \\
\hline \multirow{4}{*}{ SLN } & Anaemia & 08 & 6.06 \\
\hline & Skin rash & 01 & 0.76 \\
\hline & Raised RFT & 01 & 0.76 \\
\hline & Neuropathy & 01 & 0.76 \\
\hline \multirow{3}{*}{ ZLE } & Anaemia & 07 & 5.30 \\
\hline & Skin rash & 01 & 0.76 \\
\hline & Raised RFT & 01 & 0.76 \\
\hline \multirow{3}{*}{ TLN } & Anaemia & 05 & 3.79 \\
\hline & Raised RFT & 03 & 2.27 \\
\hline & SJS & 01 & 0.76 \\
\hline \multirow{2}{*}{ TLE } & Anaemia & 04 & 3.03 \\
\hline & Skin rash & 01 & 0.76 \\
\hline SLE & Anaemia & 03 & 2.27 \\
\hline $\mathbf{A L N}$ & Skin rash & 01 & 0.76 \\
\hline
\end{tabular}

Total no of ADRs reported $=132$.

On doing causality assessment, 90.91\% ADRs belong to possible category followed by Probable (9.09\%) (Table 4).

Table 4: Causality assessment of ADRs reported among patients receiving HAART by Naranjo's causality assessment scale.

\begin{tabular}{|lll|}
\hline Category & No. of ADRs & Percentage \\
\hline Possible & 120 & 90.91 \\
\hline Probable & 12 & 9.09 \\
\hline
\end{tabular}


$68.94 \%$ of the ADRs were of moderate followed by mild $(30.30 \%)$ grade severity (Table 5). Tuberculosis (pulmonary and extra pulmonary) $(28.47 \%)$ was the commonest diagnosed opportunistic infection among the HIV/AIDS patients (Table 6).

Table 5: Severity assessment of ADRs reported among patients receiving HAART by modified Hartwig and Siegel scale.

\begin{tabular}{|lll|}
\hline Severity of ADR & No. of ADRs & Percentage \\
\hline Mild & 40 & 30.30 \\
\hline Moderate & 91 & 68.94 \\
\hline Severe & 01 & 0.76 \\
\hline
\end{tabular}

Table 6: Pattern of opportunistic infections among patients receiving HAART.

\begin{tabular}{|lll|}
\hline Opportunistic infections & n & Percentage \\
\hline Pulmonary TB & 33 & 21.85 \\
\hline Extra pulmonary TB & 10 & 6.62 \\
\hline Pneumocystis carinii pneumonia & 04 & 2.65 \\
\hline Toxoplasmosis & 02 & 1.32 \\
\hline Herpes zoster & 02 & 1.32 \\
\hline Esophageal candidiasis & 01 & 0.66 \\
\hline
\end{tabular}

$\mathrm{n}=$ number of patients

\section{DISCUSSION}

AIDS is a global problem. Many drugs have been approved for the treatment of HIV, but the treatment of HIV/AIDS infection has become a complicated balancing act between the benefits of durable HIV suppression and the risks of drug toxicity.

In the present study, the male population $(51.66 \%)$ had higher prevalence of HIV/AIDS infection than females (48.34\%). The results are in concordance with a study conducted by Kanha MM et al. at Guntur in which $67.2 \%$ patients were male population. ${ }^{12}$

In the present study, the prevalence of HIV/AIDS infection was higher among 26-45 years age group accounting to a total of $78.81 \%$. The results are in concordance with the previous study conducted by Bhuvana $\mathrm{KB}$ et al. where majority of patients were of age group of 21-40 years $(66.5 \%)$ which indicates middle age group were affected most by HIV/AIDS infection as they are economically productive and sexually more active age group. ${ }^{4}$

In the present study, $70.19 \%$ of patients were married at the time of diagnosis HIV/AIDS infections and 19.87\% patients were widowed. Similar results were found in a study conducted by Oreagba IA et al. In that study $63 \%$ patients were married and $24 \%$ patients were single. ${ }^{1}$
In the present study, most common mode of transmission of HIV/AIDS infection was by heterosexuality in $94.04 \%$ of the patients. Other modes were probable unsafe injection (1.99\%), mother to child (1.99\%) and blood transfusion $(1.32 \%)$. Similar results were found in the study by Kapadia JD et al. they found predominant mode of transmission among adults was heterosexuality $(61.98 \%)$ and through blood transfusion $(15.7 \%) .^{13}$

In the present study, prevalence of HIV/AIDS infection was higher among illiterate and lower education status patients accounting to a total of $78.14 \%$. These findings are similar to a study conducted by Oreagba IA et al in Nigeria who found $67 \%$ of the patients were illiterate and low education background. ${ }^{1}$ This shows there is ignorance and lack of knowledge and education regarding the HIV/AIDS infection. So it is necessary to conduct mass educative programs to create awareness about the disease, its mode of transmission, the risk behaviour among sexually active age group and its preventive measures.

In present study, $78.81 \%$ of the patients had CD4 count less than 250 cells/ $\mu \mathrm{l}$ and it was observed that $62.87 \%$ ADRs were reported among these patients which is in concordance with the study conducted by Shrikanth BA et al at Kadapa, India showed that patients with CD4 count of $<250$ cells/ $\mu$ l were affected with more ADRs. ${ }^{14}$

In the present study, $31.13 \%, 29.80 \%$ and $29.14 \%$ of the HIV/AIDS patients were distributed in the WHO Clinical stages I, II and III respectively. This matches with the results found in the study Eluwa GI et al. where $27.36 \%$, $26.60 \%$ and $40.23 \%$ patients were distributed as Stage I, Stage II and Stage III respectively. ${ }^{15}$

In the present study, zidovudine+lamivudine+nevirapine (ZLN) $(86.75 \%)$ were the most commonly prescribed HAART combination followed by tenofovir+lamivudine+ effavirenz (TLE) (36.42\%) and stavudine+lamivudine+nevirapine (SLN) (34.44\%). Similar results were found in Jiyo $\mathrm{C}$ et al and Oreagba A. et al. ${ }^{16,1}$ The most common regimen prescribed among the first line HAART was the combination of zidovudine+lamivudine+nevirapine $(26.76 \%)$ followed by stavudine+lamivudine+nevirapine $(10.53 \%)$. The above findings is in accordance with our national guidelines for antiretroviral therapy which recommends ZLN as the first choice and SLN as second choice among all first line HAART regimens. Zidovudine+lamivudine+effavirenz (ZLE) $(26.49 \%)$, tenofovir+lamivudine+nevirapine (TLN) $(25.17 \%)$ and stavudine+lamivudine+effavirenz (SLE) $(9.93 \%)$ were the other combinations prescribed to the HIV/AIDS patients. ${ }^{17}$

In the present study, Out of 132 ADRs reported, commonest ADR was anaemia (76.52\%) (hematological) followed by musculoskeletal (skin rash and Steven Johnson syndrome) $10.61 \%$, raised RFT (6.06\%), GIT (nausea, vomiting, hepatomegaly) (4.55\%), neuropathy $0.76 \%$. These ADR results are in concordance with the 
Bhuvana KB et al. study in which anaemia (55.06\%) and rash $(25.3 \%)$ were found to be most common type of ADR. ${ }^{4}$ But in previous studies by Nagpal M. et al and Kiran reddy AV et al. where commonly reported ADRs belong to gastrointestinal and musculoskeletal system. ${ }^{18,19}$ This variant in the present study could be due to underreporting of ADRs or lack of awareness about ADR reporting. Hence we recommend conducting programs to educate physicians; health care professionals in ART center and patients about ADRs and pharmacovigilence program to reduce morbidity and mortality due to antiretroviral therapy.

In the present study, ZLN was the most common first line HAART combination causing ADRs reason could be ZLN $(71.97 \%)$ was the most commonly prescribed HAART combination for HIV/AIDS infection followed by SLN $(8.34 \%)$. Similar results were found in study by Kiran reddy AV et al. ${ }^{19}$ It was observed that, $37.50 \%$ ADRs were reported from the regimen ZLN followed by (35.0\%) ADRs were from SLN. SLE, ZLE and TLE were other regimens causing ADRs. Rajesh et al. has also found that those patients who received regimen containing Zidovudine and nevirapine were reported maximum number of ADRs. ${ }^{20}$

Carrying out the causality assessment using standard methods is one of the best ways to establish the causal relationship between a drug and adverse events. In the present study, on doing causality assessment using Naranjo's ADR Causality scale, $90.91 \%$ of ADRs were belonging to possible category and $9.09 \%$ ADRs belongs to probable category. Similar results were found in a study conducted by Bhuvana $\mathrm{KB}$ et al. wheremajority ADRs were found to be possible category $(89.24 \%){ }^{4}$

In order to take proper initiatives toward the management of ADRs, it is necessary to study the severity of ADRs. Modified Hartwig's and Siegel scale is widely used for this purpose which categorizes ADRs into mild, moderate and severe. In the present study, $68.94 \%$ of ADRs were moderate followed by mild $(30.30 \%)$ and severe $(0.76 \%)$. Results are in concordance with the study conducted by Patel NM et al. They found most of the ADRs were moderate $(88.69 \%)$ followed by mild $(8.39 \%)$ and severe (2.92\%) according to modified Hartwig and Siegel scale. ${ }^{9}$

Even though human immunodeficiency virus is the initial causative agent in AIDS, but most of the morbidity and mortality in AIDS cases result from opportunistic infections. Hence recognition of such pathogen is very important for clinicians and health planners to deal with the AIDS epidemic in more effective manner. In the present study, Tuberculosis (pulmonary and extrapulmonary) was the most common opportunistic infection $(28.47 \%)$. Study results are in concordance with the previous studies by Dabla $\mathrm{V}$ et al and Jiyo $\mathrm{C}$ et al tuberculosis was found to be the most common opportunistic infection. ${ }^{21,16}$ Majority of studies from India found pulmonary tuberculosis to be the most common opportunistic infection among people with HIV infection. Understanding HIV-TB co-infection is of great significance because of increasing prevalence, rapid progression of HIV disease in TB patients and challenges in treatment due to drug interactions and immune reconstitution syndrome. ${ }^{16}$

\section{CONCLUSION}

Studies on utilization pattern of HAART in ART centres appear to be lacking in our country. Thus this study provides a baseline data regarding the demographic characteristics of HIV/AIDS infection, prescribing pattern, ADR profile to various HAART regimens and opportunistic infections among HIV positive patients registered at our ART Centre. ZLN was the most frequently prescribed HAART combination. Overall results suggest that the prescribing pattern of HAART regimens was in accordance with national guidelines for antiretroviral therapy but there still remains a scope for improvement by using viral load as a biomarker along with CD4 count and we recommend a pharmacovigilance system for sustainable management of ADRs in HIV/AIDS patients as we found poor ADR reporting and variant results from the previous studies.

The present study has some limitations. The period of study was not sufficient to assess long term adverse effect profile as HIV/AIDS patients living longer with HAART. The study was conducted in only one nodal ART centre attached to a remote government medical college of Maharashtra, India. These may exclude the actual number of HIV infected patients who were on ART and experienced ADRs. We have lack to identify the potential predictors of ADRs to ART in HIV infected patients. Furthermore, we have not shown statistical significance among the parameters and large study sample must be needed for interpretation of results and to arrive at a definite conclusion. But it was our sincere effort and the results thus obtained would give feedback to clinicians and the health care decision makers regarding compliance of the treatment offered with regard to the national guidelines and thus promoting rational drug use.

\section{ACKNOWLEDGEMENT}

The authors would like to acknowledge the physicians and staff of ART Centre of SBH GMC, Dhule, Maharashtra, India.

\section{Funding: No funding sources \\ Conflict of interest: None declared \\ Ethical approval: The study was approved by the Institutional Ethics Committee}

\section{REFERENCES}

1. Oreagba IA, Usman SA, Olayemi SO, Oshikoya KA, Opanuga O, Adeyemo TA. Pharmaco epidemiology of antiretroviral drugs in a teaching 
Hospital In Lagos, Nigeria. Ghana Medical Journal. 2014;48:94-203.

2. World Health Organization [home page on internet] 2008. Available at http://www.who.int/en/. Accessed 18 March 2016.

3. Joint United Nations Programme on HIV/AIDS (UNAIDS). Global Report UNAIDS Report on the Global AIDS Epidemic-2010. Geneva: UNAIDS; 2010.

4. Bhuvana KB, Hema NG, Sangeetha. A prospective observational study of adverse drug reactions to antiretroviral therapy: type and risk factors in a tertiary care teaching hospital. Int $\mathbf{J}$ Basic Clin Pharmacol. 2014;3:380-4.

5. Prakashraju GK, Chowta MN, Rather ZA, Mubeen F. The Pattern of the initial anti-retroviral drug regimens in HIV Patients at a tertiary care hospital. Journal of Clinical and Diagnostic Research. 2012;6:1178-80.

6. Nadkar MY, Bajpai S. Antiretroviral therapy: toxicity and adherence. J Assoc Physicians India. 2009;57:375-6.

7. Divakar B, Mistry SD, Kantharia ND, Mamtarani. The study of adverse drug reactions (ADR's) in HIV patients taking highly active antiretroviral therapy in ART centre, $\mathrm{NCH}$, Surat, India. Int J Med Pharm Sci. 2012;03:9-18.

8. Monforte AA, Lepri AC, Rezza G, Pezzoti P, Antinori A, Phillips AN et al. Insights into the reasons for discontinuation of the firstly highly active anti retro viral therapy (HAART) regimen in a cohort of antiretroviral naive patients: Italian cohort of antiretroviral naove patients. AIDS. 2000;14:499-507.

9. Patel NM, Vaniya HV, Agrawal JM, Balat JD, Singh AP, Trivedi HR. Adverse drug reaction monitoring on antiretroviral therapy in human immunodeficiency virus patients in a tertiary care hospital. Int J Basic Clin Pharmacol. 2015;4:907-11.

10. Zaki SA. Adverse drug reaction and causality assessment scales. Lung India. 2011;28:152-3.

11. Hartwig SC, Siegel J, Schneider PJ. Preventability and severity assessment in reporting adverse drug reactions. Am J Hosp Pharm. 1992;49:2229-32.

12. Kanha MM, Sharmila SK. Comparative study of adverse drug reactions of two antiretroviral regimens (zidovudine+lamivudine+nevirapinevsstavudine+la mivudine+ nevirapine) In Hiv/Aids Patients. Journal of Dental and Medical Sciences. 2015;14:36-44.

13. Kapadia JD, Desai CK, Dikshit RK, Solanki MN, Shah AN. A study of utilization pattern, efficacy and safety of drugs prescribed for opportunistic infections in human immunodeficiency virus infected patients. Int $\mathrm{J}$ Med Public Health. 2014;4:200-9.

14. Srikanth BA, Babu SC, Yadav HN, Jain SK. Incidence of adverse drug reactions in human immune deficiency virus positive patients using highly active antiretroviral therapy. J Adv Pharm Technol Res. 2012;3(1):62-7.

15. Eluwa GI, Badru T, Akpoigbe KJ. Adverse drug reactions to antiretroviral therapy (ARVS) incidence, type and risk factors in Nigeria. BMC Clin Pharmacol. 2012;12(7).

16. Jiyo C, Suthar SD, Dholaria NK, Chavda DA, Bhansali NB, Gosai TR, et al. Drug utilization study of HIV positive patients registered with antiretroviral therapy centre of a tertiary care hospital. J Clin Exp Res. 2013;1:12-9.

17. Srasuebkul P, Calmy A, Zhou J, Kumarasamy N, Law M, Lim PL. Impact of drug classes and treatment availability on the rate of antiretroviral treatment change in the treat Asia HIV observational database (TAHOD). AIDS Res Ther. 2007;4:18.

18. Nagpal M, Tayal V, Kumar S, Gupta U. Adverse drug reactions to antiretroviral therapy in AIDS patients at a tertiary care hospital in India: A prospective observational study. Indian J Med Sci. 2010;64:245-52.

19. Reddy KAV, Lihite RJ, Lahkar M, Choudhury U, Swaroop K. Baruah SK. A Study on adverse drug reactions in HIV infected patients at a art centre of tertiary care hospital in Guwahati, India. Asian $\mathbf{J}$ Pharm Clin Res. 2013;6:102-4.

20. Rajesh R, Vidyasagar S, Nandakumar K. Highly active antiretroviral therapy induced adverse drug reactions in Indian human immunodeficiency virus positive patients. Pharmacy Practice (Internet). 2011;9(1):48-55.

21. Dabla V, Gupta AK and Singh I. Spectrum of opportunistic infections among HIV seropositive patients in Delhi region-a study by Delhi state AIDS control society. J Med Disord. 2015;3:1.

Cite this article as: Rathod PS, Patil PT, Lohar RP, Patil AW Current trends in highly active antiretroviral therapy in an anti-retroviral therapy centre attached to a remote government medical college of Maharashtra, India: a retrospective study. Int J Basic Clin Pharmacol 2016;5:1011-6. 